\title{
A GREEN ALTERNATIVE METHOD FOR ANALYSIS OF IVERMECTIN AND MOXIDECTIN IN ENVIRONMENTAL WATER SAMPLES USING AUTOMATIZED PRECONCENTRATION PREVIOUS MEEKC
}

\author{
Emiliano Felici ${ }^{1}$, Cristian Casado $^{2}$, Chien C. Wang ${ }^{1,3}$, Julio Raba ${ }^{1}$, María R. Gomez ${ }^{* 1,3}$ \\ ${ }^{1}$ INQUISAL, Universidad Nacional de San Luis, CONICET, Facultad de Química, \\ Bioquímica y Farmacia, Chacabuco 917, San Luis, Argentina
}

${ }^{2}$ Centro de Excelencia en Productos y Procesos de Córdoba, CEPROCOR, Santa María de Punilla, Córdoba, Argentina

${ }^{3}$ Departamento de Farmacia, Facultad de Química Bioquímica y Farmacia, UNSL

Received: MONTH DD, YYY; Revised: MONTH DD, YYY; Accepted: MONTH DD, YYY

This article has been accepted for publication and undergone full peer review but has not been through the copyediting, typesetting, pagination and proofreading process, which may lead to differences between this version and the Version of Record. Please cite this article as doi: 10.1002/elps.201600303.

This article is protected by copyright. All rights reserved.

*Corresponding author. María Roxana Gomez. Departamento de Farmacia, Facultad de Química, Bioquímica y Farmacia, Universidad Nacional de San Luis, Argentina. Tel.: +54 266 4446765. E-mail address: roxanag@unsl.edu.ar. 


\begin{abstract}
Antiparasitic drugs derived from macrocyclic lactones are widely used in livestock activities around the world. An increasing concern for local authorities is the environmental pollution as a consequence of veterinary drugs widely used in rural areas. The purpose of environmental analysis is to monitor low levels of pollutant analytes in a large number of samples. Also, due to the lipophilic characteristic of these lactones, long chain solvents are usually required for performing sample treatment before and during the analysis. Therefore, sensitive, specific, robust and environmentally friendly analytical methods are still required. In this paper, a new automatized pre-concentration methodology followed by microemulsion electrokinetic chromatography (MEECK) analysis was developed for the simultaneous separation and determination of the most used macrocyclic lactones, ivermectin (IVM) and moxidectin (MXD) in environmental water. XAD-4 resin was employed as adsorbent for the preconcentration process and ethanol was used as the eluent. In contrast to traditional analysis for IVM and MXD in this methodology non-polluting solvents were involved during the whole process and therefore, it could be considered as a contribution to green analytical
\end{abstract}


chemistry. Under optimal experimental conditions, LOD obtained for IVM and MXD were of $310^{-3} \mu \mathrm{g} / \mathrm{L}$ and $3.610^{-3} \mu \mathrm{g} / \mathrm{L}$, respectively.

Keywords: Ivermectin / MEEKC / Moxidectin / SPE / XAD-resins

\section{Introduction}

Ivermectin (IVM; Figure 1a: 22,23-dihydroavermectin Bla -80\%- and 22,23dihydroavermectin $B 1 b-20 \%-)$ and moxidectin (MXD: Figure 1b: 23-(o-methyloxime) are metabolic compounds produced by the genus Streptomyces and belong to the family of macrocyclic lactones (MLs). These products have broad spectrum antiparasitic activity and therefore have been widely used for controlling helminthes and ectoparasites in the veterinary field [1-3].

After administration, MLs are excreted unmetabolized by the animal via faeces and slowly decomposed in soil. Through rainfall, a certain amount of MLs in the soil are swept along into aquifers and rivers which become a threat to living organisms of the local ecosystems $[4,5]$.

This article is protected by copyright. All rights reserved. 
Several analytical methods have been reported for MLs determination in dairy products, commercial pharmaceutical formulations and environmental samples. As emerging contaminants in water samples, MLs are expected to be found at trace levels in the presence of potential interferences, as a result, analytical sensitivity is the most challenging aspect for MLs determination method developing [6-9].

Conventionally, analysis of MLs was carried out by HPLC-UV but when more sensitivity is required, other detection systems such as HPLC/fluorescence and HPLC/MS are also used [5]. However, exhaustive sample treatment is frequently needed, including molecule derivatization to confer emission properties [10-11]. Nevertheless, analysis of pollutants in environmental samples usually requires preconcentration procedure because of insufficient method sensitivity [10-15].

Although Capillary Electrophoresis (CE) offers an attractive alternative to HPLC, the conventional CZE (capillary zone electrophoresis) mode is not capable of separating noncharged molecules and therefore, cannot be applied to MLs analysis. Other CE modes, Micellar Electrokinetic Chromatography (MEKC) [16-18] and Microemulsion Electrokinetic Chromatography (MEEKC) [19-21] are electrodriven separation techniques that offer the possibility of highly efficient separation of charged and neutral solutes. Well known advantages of these methods compared to HPLC include no organic solvent consumption, 
ability to separate compounds of very different polarity, simplicity of sample preparation, short time analysis, among other advantages. MEKC and MEEKC, both involve stationary pseudo phases which are micelles in the first CE mode and surfactant-coated droplet in the second [3]. However, droplets used in MEEKC has some advantages over micelles, such as microemulsion stability and lower generated current.

To perform the analysis of pollutants in water samples, it is necessary to improve the sensitivity achieved in CE [22-23]. For this purpose, solid phase extraction (SPE) is one of the most commonly used techniques for sample preconcentration, due to its simplicity and efficiency to separating analytes from complex matrix. However, the preconcentration process involves an additional step in the sample analysis which is susceptible to operator error. Thus, introducing automatization to the SPE process improves the analytical performance in terms of reproducibility, accuracy and increases the number of samples that can be processed.

$\mathrm{XAD}$ resins are some of the most commonly used adsorbents in SPE technique. The selection of the adequate XAD resin allows us to preconcentrate/extract a wide variety of analytes or to remove different types of contaminants [24-27].

The purpose of this paper is to develop a highly sensitive and selective methodology for the separation and determination of IVM and MXD in environmental water samples by 
using MEEKC. In order to achieve low detection and quantification limits, an automatized sample preconcentration SPE procedure was developed and coupled to the MEEKC methodology. Taking into account that the use of toxic solvents was avoided, the whole procedure can be considered environmentally friendly.

\section{Material and methods}

\subsection{Instrumentals}

MEEKC analysis was performed on a Capillary Electrophoresis instrument (Beckman Coulter P/ACE MDQ, Beckman Instruments, Inc. Fullerton, CA) equipped with a diode array detector and a data handling system comprising an IBM personal computer and P/ACE system MDQ software. The electrophoretic separations were performed in fused-silica capillaries obtained from MicroSolv Technology Corporation (Long Branch, NJ, USA) with the following dimensions: $60 \mathrm{~cm}$ total length, $50 \mathrm{~cm}$ effective length, $75 \mu \mathrm{m}$ ID, $375 \mu \mathrm{m}$ OD.

A Gilson Minipuls 3 peristaltic pump with PVC pumping tubes and 3 valves was used for automatized sample preconcentration.

All HPLC experiments were carried out on a Gilson HPLC system equipped with a Gilson 322 controller pump operating at $1.0 \mathrm{~mL} / \mathrm{min}$, a Rheodyne $7725 \mathrm{i}$ injector with a $50 \mu \mathrm{L}$ 
sample loop, and a variable-wavelength UV-Vis 156 Gilson detector measuring at $254 \mathrm{~nm}$. The analytical column used was a Phenomenex Luna RP Si C18 column $(5 \mu \mathrm{m}, 100 \AA$, $250 \mathrm{x}$ $3 \mathrm{~mm}$ ) (Torrance, CA, USA), the separation was performed at room temperature. All calculations were performed using Matlab 6.0 software. The surface responses were graphed using Statistica 6.0 software.

A pH meter (Orion Expandable Ion Analyzer, Orion Research, Cambridge, MA, USA) Model EA940 with combined glass electrode was used for monitoring pH adjustment.

\subsection{Chemicals}

Amberlite XAD-4 resin (benzene, diethenyl-homopolymer) was purchased from Rhom-Haas (Philadelphia, USA) and used as the solid support, after activation with nitric acid $\left(\mathrm{HNO}_{3}\right)(\mathrm{c}) /$ ethanol (1:4) for about $4 \mathrm{~h}$.

Standards of IVM and ethyl 4-hydroxybenzoate were purchased from Sigma-Aldrich Co. (Burghausen, Germany) while MXD was acquired from Fluka Chemie AG (Buchs, Switzerland). Ethanol (HPLC grade) used as the eluent, sodium hydroxide $(\mathrm{NaOH})$ and hydrochloric acid $(\mathrm{HCl})$ were purchased from Merck (Darmstadt, Germany). 
The microemulsion used as background electrolyte (BGE) in MEEKC was composed by sodium tetraborate $\left(\mathrm{Na}_{2} \mathrm{~B}_{4} \mathrm{O}_{7} .10 \mathrm{H}_{2} \mathrm{O}\right)$, and sodium dodecyl sulphate $\left(\mathrm{C}_{12} \mathrm{H}_{25} \mathrm{O}_{4} \mathrm{~S}\right.$.Na, SDS $)$ as surfactant, both were acquired from Sigma Chemical Co. (St. Louis, MO, USA). Other constituents, isooctane, n-butanol and methanol were obtained from Merck (Darmstadt, Germany).

All chemicals used throughout the experiment were of analytical reagent grade; aqueous solutions were prepared using ultrapure water (18 M $\Omega \mathrm{cm}$, Milli-Q system, Millipore).

\subsection{Assay solutions}

The BGE used in MEKC for MLs separation was prepared by dissolving $0.19 \mathrm{~g}$ of sodium tetraborate and $0.58 \mathrm{~g}$ of SDS in a $100 \mathrm{~mL}$ beaker with $30 \mathrm{~mL}$ of water and $\mathrm{pH}$ was adjusted to 9.2 using $\mathrm{NaOH} 1 \mathrm{M}$. Acetonitrile and methanol were separately evaluated as organic modifiers within a range 5-20\%. The mixtures were then transferred to a $50 \mathrm{~mL}$ flask and made up with ultrapure water. The dissolution process was accelerated by ultrasonication at room temperature for $30 \mathrm{~min}$. 
The BGE used in MEEKC was prepared by dissolving $0.19 \mathrm{~g}$ of sodium tetraborate and $0.72 \mathrm{~g}$ of SDS in a $100 \mathrm{~mL}$ beaker with $30 \mathrm{~mL}$ of water. Then, $82.8 \mu \mathrm{L}$ of isooctane, 4 $\mathrm{mL}$ of $\mathrm{n}$-butanol and $2.5 \mathrm{~mL}$ of ethanol were added and $\mathrm{pH}$ was adjusted to 9.0 using $\mathrm{NaOH} 1$ M. The mixture was then transferred to a $50 \mathrm{~mL}$ flask and made up with ultrapure water. The dissolution process was accelerated by ultrasonication at room temperature for $30 \mathrm{~min}$, obtaining an optically transparent microemulsion.

Stock solutions of $1 \mathrm{mg} / \mathrm{mL}$ IVM and MXD were separately prepared by weighing an appropriate amount of each standard and dissolving them in ethanol. Standard working solutions were freshly prepared before each assay by diluting an appropriate amount of the stock standard solution with ultrapure water.

Water samples were collected from a waterhole of a rural zone (San Luis, Argentina). Each aliquot of $1000 \mathrm{~mL}$ was filtered through filter paper to eliminate solid remains, and stored under refrigeration at $5^{\circ} \mathrm{C}$. The water samples used in the validation procedure were spiked with standard solutions containing IVM and MXD at six concentration levels.

\subsection{Automatized preconcentration of IVM and MXD}

This article is protected by copyright. All rights reserved. 
A set of homemade preconcentration columns (modified $3 \mathrm{~mL}$ syringe barrel of $1 \mathrm{~cm}$ dinner diameter) was connected to the automatized sampling system as shown in Fig. 2. Each column was filled with XAD-4 resin ( $1 \mathrm{~g}$ dry weight), activated with diluted $\mathrm{HCl}$ and washed with bi-distilled water before use.

For analyte preconcentration, the valves were fixed in position 1 in order to take each sample from their respective reservoirs and send them to the column (flow rate of $3 \mathrm{~mL} / \mathrm{min}$ ). When the sampling was completed, the valves were maintained in position 1 for $30 \mathrm{~s}$ in order to purge with air the aqueous remains within the preconcentration column. Afterward, the valves were switched to position 2, which changed the channel to eluent reservoir. After discarding the first fraction of $1 \mathrm{~mL}$ of eluate, the following $15 \mathrm{~mL}$ were collected for further analysis, while the eluent stream continued for $15 \mathrm{~min}$ in order to regenerate the resins for the next sampling cycle.

\subsection{Capillary electrophoresis analysis}

The collected final ethanolic eluate was dried with a rotary evaporator. The concentrate was dissolved using $1 \mathrm{~mL}$ of BGE microemulsion prepared as described before and filtered through a $0.45 \mu \mathrm{m}$ Titan Syringe filters (Sri Inc., Eaton Town, NJ. USA), previous sample injection. 
The electrolyte solution (background electrolyte, BGE) was prepared daily and filtered as described previously. At the beginning of the day, the capillary was conditioned with $\mathrm{NaOH} 0.1 \mathrm{M}$ for $15 \mathrm{~min}$, followed by water for $15 \mathrm{~min}$, and then with BGE for $15 \mathrm{~min}$ before sample injection. To achieve high reproducibility of migration times and to avoid solute adsorption, the capillary was washed between analyses with sodium hydroxide for 2 min, followed by water for $2 \mathrm{~min}$, then equilibrated with BGE for $3 \mathrm{~min}$. Samples were pressure-injected at the anodic side at 0.5 Psi for $5 \mathrm{~s}$. A constant voltage $(30 \mathrm{kV})$ was used for all the experiments. Samples and capillary were kept at $35^{\circ} \mathrm{C}$ along the experiments. Detection was performed by DAD at a wavelength of $254 \mathrm{~nm}$.

\subsection{HPLC method}

HPLC [28] was used for the quantification of analytes in water samples and the obtained results were statistically compared against those obtained from CE. Mixed standards solutions of IVM and MXD were added over water samples within a range $0.01-0.50 \mathrm{mg} / \mathrm{L}$ and the automatized preconcentration procedure was applied. The obtained eluate was then evaporated until dried, resuspended in $1 \mathrm{~mL}$ of methanol and injected in an HPLC instrument using as a mobile phase a solution composed of acetonitrile-methanol- $\mathrm{H}_{2} \mathrm{O}$ (53:27:20). 
Sample and standard were successively injected in a volume of $50 \mu \mathrm{L}$, with a flow rate of 1 $\mathrm{mL} / \mathrm{min}$.

\section{Results and discussion}

\subsection{Optimization of automatized preconcentration of IVM and MXD}

XAD resins allow the separation of hydrophobic as well as hydrophilic compounds depending on their affinity to the polymer. The selection of the appropriate resin for IVM and MXD was based on their adsorption-desorption performance. Taking into account the hydrophobic nature for most MLs, it could be assumed that non-polar XAD resins have good affinity to studied analytes. However, the selectivity of polymeric resins could also be affected by several factors, such as solvent nature, $\mathrm{pH}$, and ionic strength. The adsorption capability for IVM and MXD of some commercially available XAD resins (XAD-2, 4 and 7) was tested by comparing the UV absorption of analytes in aqueous solutions previously and after preconcentration process. The results showed that about $90 \%$ of spiked analytes in aqueous solution were retained by XAD-4 and XAD-2, but only 15\% for polar resin XAD-7. The results confirmed the high affinity of IVM and MXD for non-polar XAD-4 and XAD-2, so they could easily be extracted from aqueous medium.

This article is protected by copyright. All rights reserved. 
On the other hand, IVM and MXD desorption from XAD resins was also studied by their elution profile. As IVM behaves similarly to MXD and it is the most representative compound among MLs, it was taken as the reference in further preconcentration studies. For XAD-4, $90 \%$ of the total spiked analytes eluted within the fraction 1-12 mL, with a maximum concentration at $6 \mathrm{~mL}$ of eluate (Fig. 3A). For XAD-2, the elution profile showed a slower desorption process due to its high affinity to MLs. Therefore, XAD-4 was selected for further studies not just because of its efficacy on retaining IVM and MXD, but also because of the rapid desorption in comparison to the studied resins.

Effective length of preconcentration column is determined by the amount of resin packed inside the column. Insufficient length leads to a low retention efficacy, while peak broadening and tailing effect in the elution profile can be observed when it exceeds an appropriate extent. Thus, the quantity of XAD-4 resin to be used was optimized relying on the adsorption and desorption profile obtained for IVM and MXD in the range of 0.1 to $1.5 \mathrm{~g}$ dry weight (Fig. 3B). As result, $1 \mathrm{~g}$ of XAD-4 proved to be the most adequate, giving a linear response for MLs within a concentration range of $0.01-0.20 \mathrm{mg} / \mathrm{L}$.

Although parameters like sample volume and flow rate directly affect the method sensitivity, their selection was a compromise between good analytical response and reasonable analysis time. As shown in Figure 3C, the increase of flow rate mildly disfavors 
analytes retention until $3.5 \mathrm{~mL} / \mathrm{min}$, which markedly affected resin retention capacity. Therefore, sample stream was fixed at $3 \mathrm{~mL} / \mathrm{min}$. Likewise increasing sample volume could proportionally improve method sensitivity but extend analysis time. Therefore, sample volume of $1 \mathrm{~L}$ was selected for this study, since it provides a suitable analytical signal within the studied concentration range.

Eluent was selected considering the analytes desorption efficacy from XAD-4 supplied for different organic solvents. Long-chain organic solvents typically used as eluents in SPE were avoided due to its potential risk for the operator and environment, being replaced in this study by methanol, ethanol, acetonitrile, acetone and their mixtures at different proportions. Among the tested solvents, ethanol was selected not just because of its effectiveness on removing MLs from XAD-4 resin, but also due to its low toxicity, cheapness and its wide availability.

The performance of the automatized preconcentration was evaluated by means of the preconcentration factor $(\mathrm{PF})$ and recovery factor $(\mathrm{RF} \%)$ experimentally calculated. A theorical $\mathrm{PF}\left(\mathrm{PF}_{\mathrm{t}}\right)$ was obtained from the ratio of initial volume $\left(\mathrm{V}_{0}\right)$ to final volume $\left(\mathrm{V}_{\mathrm{f}}\right)$. Furthermore, the analyte concentration determined in both volumes by using the proposed methodology, allowed calculation to the real $\mathrm{PF}\left(\mathrm{PF}_{\mathrm{r}}\right)$, and to obtain the RF\% from the expression $\mathrm{PF}_{\mathrm{r}} / \mathrm{PF}_{\mathrm{t}} \mathrm{x} 100$ (Table 1). 


\subsection{Capillary electrophoresis analysis}

\subsubsection{MEKC}

MEKC mode might be considered for the analysis of IVM and MXD because it is mainly used for the separation of neutral compounds. SDS was the selected surfactant for the preparation of the BGE micellar solution because it has many advantages such as good stability, low UV absorbance, high solubilizing capability, and availability of good quality reagent.

The influence of tetraborate concentration on resolution was tested within the range 0.01-0.06 $\mathrm{mol} / \mathrm{L}$, at higher concentrations, analysis time increased and resolution did not improve, thus a $0.01 \mathrm{~mol} / \mathrm{L}$ tetraborate buffer was chosen.

The effect of SDS concentration on IVM and MXD separation was evaluated from 0.02 to $0.06 \mathrm{~mol} / \mathrm{L}$. At a concentration of $0.06 \mathrm{~mol} / \mathrm{L}$ of SDS not just an uncompleted separation was achieved, but the analysis time as well as the current increased greatly. Under these conditions, an undesirable effect of peak broadening was also observed (Fig. 4). Experimental parameters such as the applied voltage, capillary temperature and injection time were tested but no appreciable improvements were obtained on the resolution. This result can 
be attributed to the fact that IVM and MXD are structurally related analogues which hinder their separation. As a consequence, the MEEKC mode was taken in consideration for the following assays.

\subsubsection{MEEKC}

In contrast to micelles surface, the droplet surface which form microemulsion is less rigid and therefore, facilitates penetration of analytes inside the hydrophobic core, improving the performance of the partitioning process. As a result, some analogues that were not able to be separated by MEKC could be resolved using a microemulsion.

It is known that several experimental conditions such as temperature and microemulsion composition affect the separation performance in MEEKC. In order to obtain a physically stable microemulsion with good resolution, $\mathrm{pH}$ and aqueous phase composition, nature and concentration of oil phase, surfactant and co-surfactant were studied. CE instrumental conditions were also optimized for improving separation efficacy for IVM and MXD.

The effect of sodium tetraborate concentration in microemulsion was studied within a range of 0.01 to $0.03 \mathrm{~mol} / \mathrm{mL}$ and the influence of the $\mathrm{pH}$ was evaluated between $8.0-10.0$ to establish the optimal conditions. Longer migration time and higher generated current were 
observed with increasing sodium tetraborate concentration (Fig. 5A). When $\mathrm{pH}$ below 9.0 was used, analytes migration time increased without improvements on resolution (Fig. 5B). Based on these results, a concentration of $0.01 \mathrm{~mol} / \mathrm{mL}$ of sodium tetraborate at $\mathrm{pH} 9.2$ was chosen for the microemulsion preparation for further studies.

To achieve an optically transparent microemulsion, it is necessary to form small droplets of oil phase in the order of nano-scale in the aqueous phase. Surfactants facilitate droplet formation by lowering the surface tension. Also, a short-chain alcohol is added as cosurfactant, which further lowers surface tension and stabilizes the microemulsion system. SDS was added as the surfactant within a range of 0.03 to $0.06 \mathrm{~mol} / \mathrm{mL}$ while two different cosurfactants, butanol and pentanol, were also evaluated.

Stable microemulsions were obtained from SDS concentrations greater than 0.03 $\mathrm{mol} / \mathrm{mL}$. Above this value, although a higher resolution of the analytes was observed when increasing the SDS concentration, a detrimental increase in current generated and the migration times was found (Fig. 5C). However, when using a concentration of SDS higher than $0.06 \mathrm{~mol} / \mathrm{mL}$, the separation lacked reproducibility due to system instability. Hence, SDS $0.04 \mathrm{~mol} / \mathrm{mL}$ was established as a working concentration that allowed a baseline separation of IVM and MXD. 
To evaluate the influence of the short-chain alcohol, n-butanol and pentanol were assayed within a concentration range of $0.8-1 \mathrm{~mol} / \mathrm{mL}, \mathrm{n}$-butanol at $0.93 \mathrm{~mol} / \mathrm{mL}$ was chosen due to its performance (Fig. 5D) and availability in the laboratory.

With the aim of improving resolution, organic solvents were separately added in the microemulsion buffer. Ethanol, methanol and acetonitrile were tested within a concentration range of $3-10 \%(\mathrm{v} / \mathrm{v})$. As a result, the baseline separation of the analytes could be achieved by using ethanol 3\% (Fig. 5E).

As oil phase, isooctane and heptane were assayed, showing longer analysis time when heptane was used in the microemulsion (Fig. 5F). Thus, isooctane was selected for further studies within a concentration range of $0.01-0.04 \mathrm{~mol} / \mathrm{mL}$, selecting a concentration of 0.01 $\mathrm{mol} / \mathrm{mL}$ because of its greater signal-noise relation.

Moreover, the generated current and thus the joule heating decreased with the addition of an organic solvent.

As time and pressure injection are related to the sample volume injected, higher values improved method sensitivity but a baseline separation was not obtained. Also, the effect of the applied voltage and the temperature on the analytes separation was evaluated. The applied voltage was studied within a range $15-30 \mathrm{kV}$ while the capillary was maintained between $15-35^{\circ} \mathrm{C}$. Faster analysis time can be obtained using higher temperature and/or 
voltage (Fig. 5G). Hence, the experimental parameters selected to further studies were hydrodynamic injection at 0.5 Psi during $5 \mathrm{~s}$, applied voltage of $30 \mathrm{kV}$ and the capillary temperature was maintained at $35^{\circ} \mathrm{C}$. The base line separation of IVM and MXD was achieved below 10 min under optimal experimental condition (Fig. 5H).

\subsection{Validation of CE methodology}

The Internal Standard (IS) method was applied to guarantee the results for the quantitative CE analysis of IVM and MXD. For this purpose, ethyl 4-hydroxybenzoate was chosen as IS due to its maximum UV absorption band in the region of $245 \mathrm{~nm}$ and its different migration time from IVM and MXD.

The calibration plots were established under the optimal experimental conditions described, calculated as the ratio of the corrected peak area of the analyte to that of internal standard $\left(\mathrm{A}_{\text {Analyte }} / \mathrm{A}_{\mathrm{IS}}\right)$ versus the analyte concentration at six levels in a range of 0.01-500 $\mu \mathrm{g} / \mathrm{L}$ for IVM and $0.012-500 \mu \mathrm{g} / \mathrm{L}$ for MXD. Good linear relationship of $\mathrm{A}_{\text {Analyte }} / \mathrm{A}_{\mathrm{IS}}$ versus analyte concentration was obtained, being $\mathrm{r}^{2}=0.999$ and 0.998 for both IVM and MXD, respectively. 
Detection and quantification limits were calculated as the analyte concentration that gives rise to peak response with signal-to-noise ratio of 3 and 10, respectively (Table 2). As it can be seen, the LOD and LOQ obtained by applying the proposed methodology to the IVM and MXD quantification, have the adequate sensitivity for environmental samples analysis. Previously, several analytical methods for IVM and others MLs were reported. Some of them were summarized in Table 3 in order to compare their analytical parameters with those obtained by applying the proposed methodology. As it can be seen, except for two-step extraction with LC-MSD SL Quad analysis [15] the proposed methodology presents better analytical sensitivity when it is compared to the literature data from Table 3 . In addition, nonpolluting solvents were involved in MEEKC analysis, which represent as advantage to those mentioned in the Table 3, taking in account that all chromatographic method mentioned involve the use of organic solvent.

Precision was expressed as \% relative standard deviation (\%R.S.D.), which was calculated for the migration times and the $A_{\text {Analyte }} / A_{\text {IS }}$ ratio of corrected peak areas obtained for each analyte. The precision was evaluated in terms of method repeatability (intraday precision) and intermediate precision (interday precision). The mean value and R.S.D. for method repeatability were obtained from five separate runs each day, while values for intermediate precision were obtained during 5 consecutive days. Results in Table 2 indicate an adequate precision for the methodology.

This article is protected by copyright. All rights reserved. 
The effect of sample matrix on the accuracy of the method was investigated by spiking a mixture of known amounts of IVM and MXD and applying the developed procedure as described in section 2.3. Each MEEKC experiment was carried out by triplicate and the results are shown in Table 4. These results showed good accuracy and appropriate selectivity of the method with the recoveries for spiked standards ranging from 10-200 $\mu \mathrm{g} / \mathrm{L}$ with R.S.D. $<2.3 \%$.

\subsection{Application to real samples}

The applicability of the present MEEKC methodology for IVM and MXD determination in environmental water samples was checked against HPLC. As studied analytes were not found at concentrations higher than the calculated LOQ, standard addition method at six levels of analytes concentrations within 10-200 $\mu \mathrm{g} / \mathrm{L}$ was applied. Using paired t-test analysis at 95\% confidence interval of the mean, MEEKC and HPLC methods gave non-significant difference in the determined amounts of analytes in water samples $\left(\mathrm{P}_{\mathrm{IVM}}\right.$ value $=0.16 ; \mathrm{T}$ value $=1.547 ; 5$ degrees of freedom $)\left(\mathrm{P}_{\mathrm{MXD}}\right.$ value $=0.16 ; \mathrm{T}$ value $=1.547 ; 5$ degrees of freedom). The obtained linear plot for HPLC determination was $y=94,122.45 x+$ $46.94\left(r^{2}=0.9997\right)$ for IVM and $y=79,052.47 x+48.8(r 2=0.9990)$ for MXD. 


\section{Concluding remarks}

The proposed method provides a green and sensitive automatized SPE-MEEKC methodology for the analysis of two main antibiotic drugs belonging to the macrocyclic lactones family, IVM and MXD. XAD-4 resin was applied for SPE for which the whole procedure was automatized in order to reduce the operational errors and costs. In contrast to conventional preconcentration step for these drugs, non-pollutant solvents were involved. A high preconcentration factor over 800 was achieved, indicating the efficiency of this extraction procedure. Additionally, the low sample and reagent consumption, faster analysis time with highly resolution efficiency associated to $\mathrm{CE}$ methodologies make this methodology a green chemistry alternative to the conventional analysis.

\section{Acknowledgements}

The present work has been carried out under the financial support of National University of San Luis (Project N $N^{o}$ 2/1112), CONICET (PIP 11220110100114) and CEPROCOR (Centro de Excelencia en Procesos y Productos de Córdoba, Argentina). 
Authors wish to thank CEPROCOR and INQUISAL-CONICET (Instituto de Química de San LuisConsejo Nacional de Investigaciones Científicas y Tecnológicas).

\section{References}

[1] Molyneux, D., Taylor, H.R., Trends Parasitol. 2015, 31, 1.

[2] Beynon, S. A., Vet. Parasitol. 2012, 189, 113-124.

[3] Kaufmann, A., Butcher, P., Maden, K., Walker, S., Widmer, M., Talanta 2011, 85, 9911000.

[4] Zrnčić, M., Gros, M., Babić, S., Kaštelan-Macan, M., Barcelo, D., Petrović, M., Chemosphere 2014, 99, 224-232.

[5] Furlani, R.P., Dias, F.F., Nogueira, P.M., Gomes, F.M., Tfouni, S.A., Camargo, M.C., Food Control 2015, 48, 43-47.

[6] Castro-Puyana, M., Crego, A.L., Marina, M.L., Electrophoresis 2008, 29, 274-293.

[7] Prasse, C., Löffler, D., Ternes, T.A., Chemosphere 2009, 77, 1321-1325.

This article is protected by copyright. All rights reserved. 
[8] Zhan, J., Yu, X.J., Zhong, Y.Y., Zhang, Z.T., Cui, X.M., Peng, J.F., Zhu, Y., J. Chromatog. B 2012, 906, 48-57.

[9] Stong, J.D., Ana. Chem. 1987, 59, 266-270.

[10] Perez, L., Palma, C., Villegas, R., Vega, M., Perez, R., Arch. Med. Vet. 2006, 38, 143150.

[11] Furlani, R.P., Dias, F.F., Nogueira, P.M., Gomes, F.M., Tfouni, S.A., Camargo, M.C., Food Control 2015, 48, 43-47.

[12] Raich-Montiu, J., Krogh, K.A., Granados, M., Jönsson, J.A., Halling-Sørensen, B., J. Chromatogr. A 2008, 1187, 275-280.

[13] Zhan, J., Yu, X. J., Zhong, Y. Y., Zhang, Z. T., Cui, X. M., Peng, J. F., Feng, J. F., Liu, X. T., Zhu, Y., J. Chromatogr. B 2012, 906, 48-57.

[14] Imperiale, F., Sallovitz, J., Lifschitz, A., Lanusse, C., Food Addit. Contam. 2002, 19, 810-818.

[15] Gravell, A., Validated method for determination of veterinary medicines in the environment using the agilent LC-MSD Quad and ion trap, Agilent Technologies, 2005. 
[16] Wu, Y., Zhai, Y., Zhang, Y., Zhang, H., Jing, H., Chen, A., J. Chromatogr. B 2014, 965, 254-259.

[17] Nussbaumer, S., Fleury-Souverain, S., Schappler, J., Rudaz, S., Veuthey, J.L., Bonnabry, P., J. Pharmaceut. Biomed. 2011, 55, 253-258.

[18] Kitagawa, F., Otsuka, K., J. Chromatogr. B 2011, 879, 3078-3095.

[19] Ryan, R., Altria, K., McEvoy, E., Donegan, S., Power, J., Electrophoresis 2013, 34, 159177.

[20] Liotta, E., Gottardo, R., Seri, C., Rimondo, C., Miksik, L., Serpelloni, G., Tagliaro, F., Forensic. Sci. Int. 2012, 220, 279-283.

[21] Sirén, H., Vesanen, S., Suomi, J., J. Chromatogr. B 2014, 945, 199-206.

[22] Hernández-Borges, J., García-Montelongo, F.J., Cifuentes, A., Rodríguez-Delgado, M.Á., J. Chromatogr. A 2005, 1070, 171-177.

[23] Acunha, T., Simó, C., Ibáñez, C., Gallardo, A., Cifuentes, A., J. Chromatogr. A 2016, 1428, 326-335.

[24] dos Reis, L.G.T., Gallart-Mateu, D., Pacheco, W.F., Pastor, A., de la Guardia, M., Cassella, R.J., Microchem. J. 2013, 110, 494-500.

This article is protected by copyright. All rights reserved. 
[25] Wang, C.C., Sombra, L., Fernandez, L., Talanta 2012, 98, 247-252.

[26] Xiao, F., Davidsavor, K.J., Park, S., Nakayama, M., Phillips, B.R., J. Colloid Interf. Sci. $2012,368,505-511$.

[27] Guo, G., Camblin, M., Han, M., Meert, C., Park, S., in: Ahuja, S. and Jimilar MI (Eds.), Capillary electrophoresis methods for pharmaceutical analysis, Academic Press, 2008, chapter 14.

[28] USP 35/NF30, U. S. Pharmacopoeia, 2012, Vol 3, pp. 4036-4038.

Table 1: Preconcentration parameters. Optimization of preconcentration variables and performance.

\begin{tabular}{|l|c|c|}
\hline \multicolumn{1}{|c|}{ Variables } & Studied range & Optimum value \\
\hline XAD resin quantity (g, dry weight) & $0.50-1.50$ & 1.00 \\
\hline Sample flow rate (mL/min) & $1.00-4.00$ & 3.00 \\
\hline Sample volume (L) & $1.00-3.00$ & 1.00 \\
\hline Eluent flow rate (mL/min) & $1.00-4.00$ & 3.00 \\
\hline \multicolumn{2}{|c|}{ Preconcentration performance } \\
\hline $\mathrm{FPt}^{\mathrm{a}}$ & $\mathrm{FPr}$ & $\mathrm{FR} \%{ }^{\mathrm{c}}$ \\
\hline 1,000 & 812.5 & $81.25 \pm 2.0$ \\
\hline
\end{tabular}

This article is protected by copyright. All rights reserved. 
${ }^{\mathrm{a}} \mathrm{V}_{\mathrm{f} /} \mathrm{V}_{0}$

${ }^{\mathrm{b}} \mathrm{C}_{\mathrm{f}} / \mathrm{C}_{0}$

${ }^{\mathrm{c}} \mathrm{FP}_{\mathrm{r}} / \mathrm{FP}_{\mathrm{t}} \times 100$

Table 2: Method validation regarding linearity, LOD, LOQ, repeatability and intermediate precision (migration time and peak area) for IVM and MXD.

\begin{tabular}{|c|c|c|c|c|c|c|c|c|c|c|}
\hline \multirow{3}{*}{ Analyte } & \multirow{2}{*}{\multicolumn{3}{|c|}{ Regression equation }} & \multirow{3}{*}{$\begin{array}{l}\text { Linear } \\
\text { range } \\
(\mu \mathrm{g} / \mathrm{L})\end{array}$} & \multirow{3}{*}{$\begin{array}{l}\text { LOD } \\
(\mu \mathrm{g} / \mathrm{L})\end{array}$} & \multirow{3}{*}{$\begin{array}{l}\text { LOQ } \\
(\mu \mathrm{g} / \mathrm{L})\end{array}$} & \multicolumn{4}{|c|}{ Precision $^{\mathrm{a}}$} \\
\hline & & & & & & & \multicolumn{2}{|c|}{$\begin{array}{c}\text { Migration time } \\
\text { R.S.D.\% }\end{array}$} & \multicolumn{2}{|c|}{$\begin{array}{l}\text { Peak area } \\
\text { R.S.D.\% }\end{array}$} \\
\hline & Slope & Intercept & $\mathrm{r}^{2}$ & & & & $\operatorname{Rep}^{\mathrm{b}}$ & $\mathrm{IP}^{\mathrm{c}}$ & $\operatorname{Rep}^{b}$ & $\mathrm{IP}^{\mathrm{c}}$ \\
\hline IVM & 5.446 & 0.0012 & 0.999 & $0.010-500$ & $3.010^{-3}$ & 0.010 & 0.73 & 1.05 & 1.88 & 2.50 \\
\hline MXD & 4.569 & 0.0125 & 0.998 & $0.012-500$ & $3.610^{-3}$ & 0.012 & 1.20 & 1.23 & 1.55 & 2.16 \\
\hline
\end{tabular}

${ }^{\mathrm{a}} \mathrm{n}=5$

${ }^{\mathrm{b}}$ Rep $=$ repeatability

${ }^{\mathrm{c}} \mathrm{IP}=$ intermediate precision

This article is protected by copyright. All rights reserved. 
Table 3: Analytical parameters of reported and proposed method for IVM analysis.

\begin{tabular}{|l|c|c|c|c|c|}
\hline $\begin{array}{l}\text { Sample pretreatment and } \\
\text { preconcentration procedure }\end{array}$ & Analysis method & $\begin{array}{c}\text { LOQ } \\
(\mu \mathrm{g} / \mathrm{L})\end{array}$ & $\begin{array}{c}\mathrm{LOD} \\
(\mu \mathrm{g} / \mathrm{L})\end{array}$ & Applied sample & Reference \\
\hline $\begin{array}{l}\text { SPE (SupelcleanLC18®), } \\
\text { fluorescence derivatization }\end{array}$ & $\begin{array}{c}\text { HPLC- } \\
\text { Fluorescence }\end{array}$ & 0.043 & 0.037 & Milk & {$[10]$} \\
\hline Fluorescence derivatization & HPLC-FLD & 5 & 1.2 & Milk & {$[11]$} \\
\hline $\begin{array}{l}\text { Hollow fibre supported liquid } \\
\text { membrane }\end{array}$ & LC-MS/MS & 0.75 & 0.2 & $\begin{array}{c}\text { Environmental } \\
\text { water }\end{array}$ & {$[12]$} \\
\hline Two-step precipitation & $\begin{array}{c}\text { UPLC-ESI- } \\
\text { MS/MS }\end{array}$ & 2 & -- & Milk & {$[13]$} \\
\hline Chemical extraction & HPLC & 0.1 & -- & Milk & {$[14]$} \\
\hline $\begin{array}{l}\text { SPE further second extraction } \\
\text { technique using Dionex } \\
\text { Accelerated Solvent Extraction }\end{array}$ & $\begin{array}{c}\text { LC-MSD SL } \\
\text { Quad }\end{array}$ & -- & 0.0002 & $\begin{array}{c}\text { Environmental } \\
\text { water }\end{array}$ & {$[15]$} \\
\hline Automatized SPE & MEEKC & 0.01 & 0.003 & $\begin{array}{c}\text { Environmental } \\
\text { water }\end{array}$ & {$[*]$} \\
\hline
\end{tabular}

*Proposed method

Table 4: Method validation regarding accuracy. Recovery test.

\begin{tabular}{|c|c|c|c|c|c|c|}
\hline Aliquots $^{\mathrm{a}}$ & $\begin{array}{c}\text { IVM } \\
\text { added }^{\mathrm{mg} / \mathrm{L})}\end{array}$ & $\begin{array}{c}\text { IVM } \\
\text { recovered }^{\mathrm{b}} \\
(\mathrm{mg} / \mathrm{L})\end{array}$ & $\begin{array}{c}\text { Recovery }^{\mathrm{c}} \\
\pm \mathrm{RSD}(\%)\end{array}$ & $\begin{array}{c}\text { MXD } \\
\text { added }^{\mathrm{mg} / \mathrm{L})}\end{array}$ & $\begin{array}{c}\text { MXD } \\
\text { recovered }^{\mathrm{b}} \\
(\mathrm{mg} / \mathrm{L})\end{array}$ & $\begin{array}{c}\text { Recovery }^{\mathrm{c}} \\
\pm \mathrm{RSD}(\%)\end{array}$ \\
\hline I & 0.21 & 0.208 & $99.0 \pm 2.0$ & 0.204 & 0.199 & $97.5 \pm 2.3$ \\
\hline II & 0.105 & 0.103 & $98.1 \pm 2.2$ & 0.102 & 0.099 & $97.0 \pm 1.8$ \\
\hline III & 0.0525 & 0.051 & $97.1 \pm 1.8$ & 0.051 & 0.049 & $96.0 \pm 2.0$ \\
\hline
\end{tabular}

This article is protected by copyright. All rights reserved. 


\begin{tabular}{|c|c|c|c|c|c|c|}
\hline IV & 0.0262 & 0.025 & $98.0 \pm 2.1$ & 0.025 & 0.025 & $98.0 \pm 2.1$ \\
\hline $\mathrm{V}$ & 0.0105 & 0.010 & $99.0 \pm 1.9$ & 0.010 & 0.010 & $98.0 \pm 2.2$ \\
\hline
\end{tabular}

${ }^{\mathrm{a}}$ aliquots volume: $1 \mathrm{~L}$

${ }^{\mathrm{b}}$ mean value

${ }^{\mathrm{c}} 100 \times$ [(found value - base value) /added value]

Figure. 1 Representative macrocyclic lactones. Where: (A) Ivermectine; (B) Moxidectine.

This article is protected by copyright. All rights reserved. 
Fig. 1

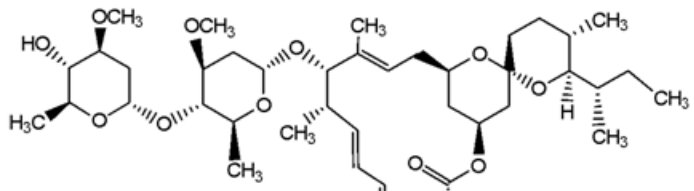

$B_{1 \mathrm{a}}$<smiles>C/C=C1/CO[C@H]2[C@@H](O)[C@H](O)C(C)=C[C@H](C)[C@]12O</smiles>

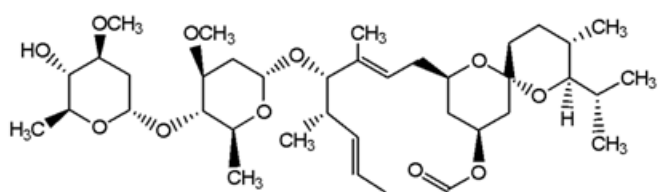

$B_{1 b}$
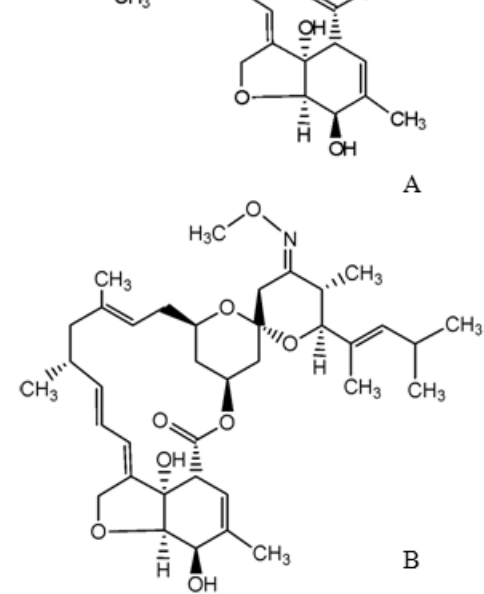

Figure. 2 Scheme pre-concentration IVM and MXD using XAD-4 resin.

This article is protected by copyright. All rights reserved. 
Fig. 2
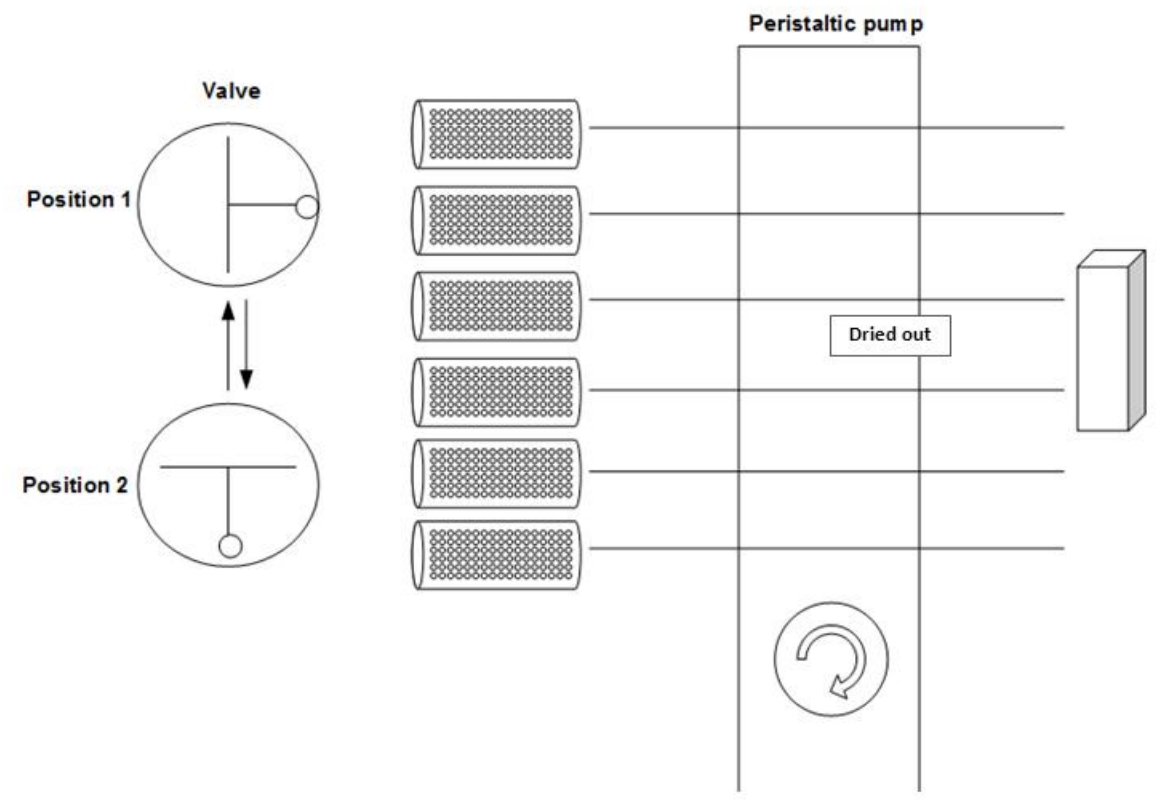

Figure. 3 Elution profile of IVM, where: (A) influence of resins nature: using XAD-2, XAD-4 and XAD-7 (1 $\mathrm{g}$ of each respective resin); (B) influence of XAD-4 resin quantity varying from 1-1.5 $\mathrm{g}$; (C) influence of sample flow rate: varying from $1-4 \mathrm{~mL} / \mathrm{min}$. Experimental condition: eluent: ethanol, DAD at $254 \mathrm{~nm}$.

This article is protected by copyright. All rights reserved. 
Fig. 3
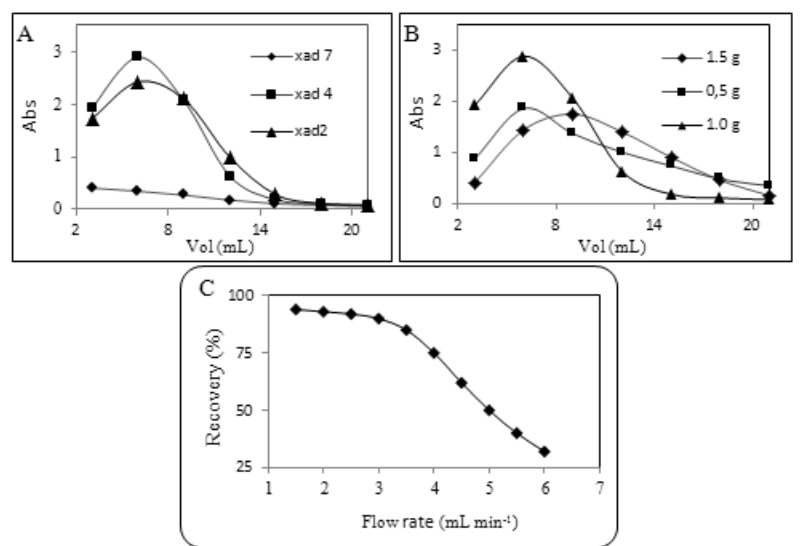

Figure. 4 Influence of SDS concentration on IVM $(0.2 \mu \mathrm{g} / \mathrm{L})$ and MXD $(0.2 \mu \mathrm{g} / \mathrm{L})$ resolution by MEKC. Experimental condition: BGE sodium tetraborate buffer $0.01 \mathrm{~mol} / \mathrm{L} \mathrm{pH} \mathrm{9.2,} \mathrm{SDS} \mathrm{0.025-0.05} \mathrm{mol/L,}$ methanol 3\%; total capillary length $60 \mathrm{~cm}, 75 \mu \mathrm{m}$ ID, hydrodynamic injection at 0.5 Psi during $5 \mathrm{~s}$; constant voltage $30 \mathrm{kV}$; capillary TO $35^{\circ} \mathrm{C}$, detection by DAD at $254 \mathrm{~nm}$.

This article is protected by copyright. All rights reserved. 
Fig. 4

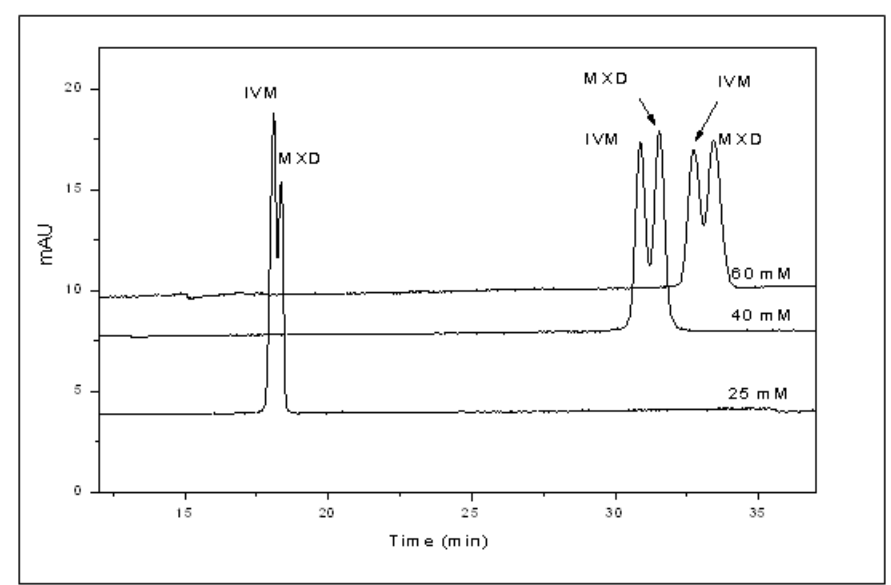

Figure. 5 Electropherograms of MEEKC separation for IVM and MXD at different experimental condition, where: (A) Concentration of sodium tetraborate $0.01-0.03 \mathrm{~mol} / \mathrm{L}, \mathrm{pH} 9.2$, SDS $0.04 \mathrm{~mol} / \mathrm{L}$, isooctane $0.01 \mathrm{~mol} / \mathrm{L}$, n-buthanol $0.93 \mathrm{~mol} / \mathrm{L}$, methanol 5\%, To $25^{\circ} \mathrm{C}$; (B) $\mathrm{pH} 8.0-10.0$, concentration of sodium tetraborate $0.01 \mathrm{~mol} / \mathrm{L}$, SDS $0.06 \mathrm{~mol} / \mathrm{L}$, isooctane $0.01 \mathrm{~mol} / \mathrm{L}$, $\mathrm{n}$-buthanol $0.93 \mathrm{~mol} / \mathrm{L}$, methanol $5 \%$, To $25^{\circ} \mathrm{C}$; (C) Concentration of SDS $0.04-0.06 \mathrm{~mol} / \mathrm{L}$, sodium tetraborate $0.01 \mathrm{~mol} / \mathrm{L}, \mathrm{pH} 9.2$, isooctane 0.01 $\mathrm{mol} / \mathrm{L}$, nbuthanol $0.93 \mathrm{~mol} / \mathrm{L}$, methanol 5\%, To 25\% ; (D) Concentration of n-butanol 0.8-1 mol$/ \mathrm{mL}$, sodium tetraborate $0.01 \mathrm{~mol} / \mathrm{L}$, $\mathrm{pH} 9.2$, SDS $0.04 \mathrm{~mol} / \mathrm{L}$, isooctane $0.01 \mathrm{~mol} / \mathrm{L}$, methanol $5 \%, \mathrm{TO}^{\circ} 25^{\circ} \mathrm{C}$; (E) Nature and concentration of alcohol: methanol/ethanol 3-5\%, sodium tetraborate $0.01 \mathrm{~mol} / \mathrm{L}, \mathrm{pH}$ 9.2, SDS $0.04 \mathrm{~mol} / \mathrm{L}$, isooctane $0.01 \mathrm{~mol} / \mathrm{L}$, $\mathrm{n}$-buthanol $0.93 \mathrm{~mol} / \mathrm{L}$, To $25^{\circ} \mathrm{C} ;(\mathrm{F})$ Oil phase nature: heptane/isooctane $0.01 \mathrm{~mol} / \mathrm{L}$, sodium tetraborate $0.01 \mathrm{~mol} / \mathrm{L}, \mathrm{pH} 9.2$, SDS $0.04 \mathrm{~mol} / \mathrm{L}, \mathrm{n}$-buthanol 0.93 $\mathrm{mol} / \mathrm{L}$, ethanol $3 \%$, To $25^{\circ} \mathrm{C} ;(\mathrm{G})$ Capillary temperature $25-35^{\circ} \mathrm{C}$, sodium tetraborate $0.01 \mathrm{~mol} / \mathrm{L}, \mathrm{pH}$ 9.2 , SDS $0.04 \mathrm{~mol} / \mathrm{L}$, isooctane $0.01 \mathrm{~mol} / \mathrm{L}$, $\mathrm{n}$-buthanol $0.93 \mathrm{~mol} / \mathrm{L}$, ethanol $3 \%$; $(\mathrm{H})$ Optimal condition: sodium tetraborate $0.01 \mathrm{~mol} / \mathrm{L}, \mathrm{pH} 9.2$, SDS $0.04 \mathrm{~mol} / \mathrm{L}$, isooctane $0.01 \mathrm{~mol} / \mathrm{L}$, $\mathrm{n}$-buthanol $0.93 \mathrm{~mol} / \mathrm{L}$, ethanol 3\%, TO $35^{\circ} \mathrm{C}$; Experimental condition: total capillary length $60 \mathrm{~cm}, 75 \mu \mathrm{m}$ ID, hydrodynamic injection at 0.5 Psi during $5 \mathrm{~s}$; constant voltage $30 \mathrm{kV}$; detection by DAD at $254 \mathrm{~nm}$.

This article is protected by copyright. All rights reserved. 
Fig. 5
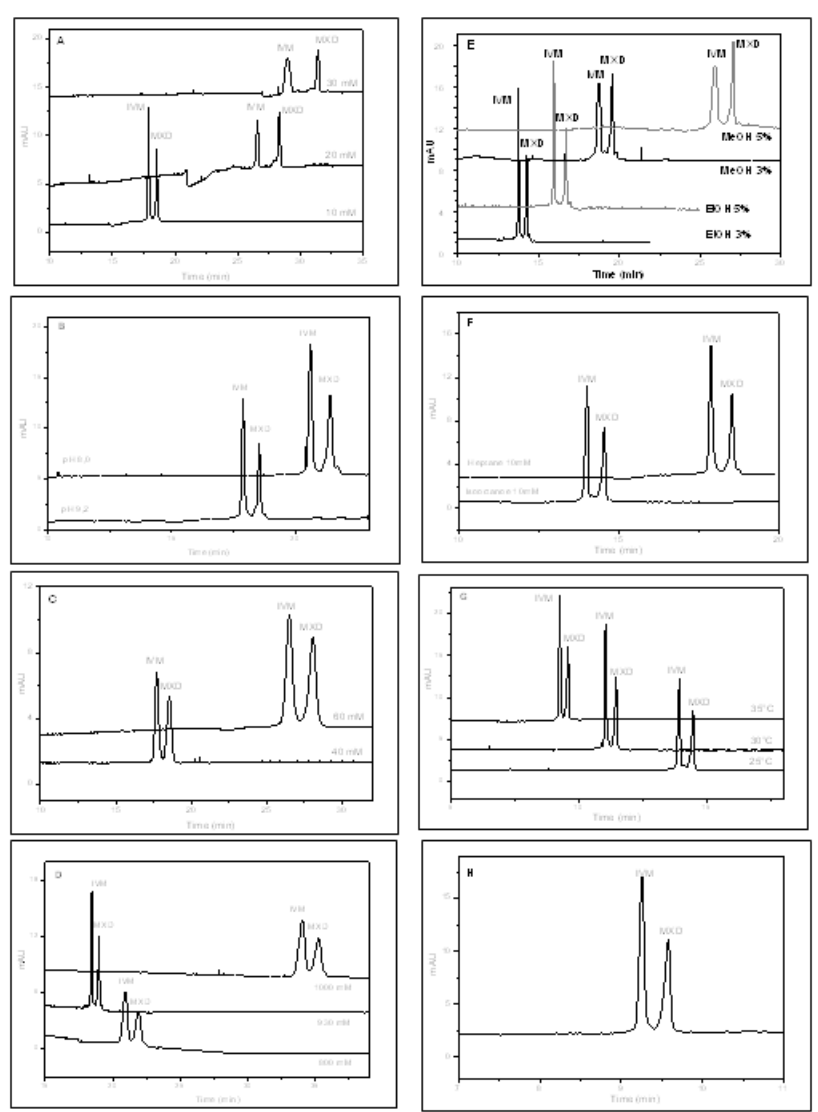

This article is protected by copyright. All rights reserved. 